clinical world have traditionally progressed via the academic or clinical route, and often seemingly through seniority alone. For a long time, leadership was seen as 'management', a term equated with a challenge to medical authority and primarily aimed at cutting costs. Those clinicians who move into management roles, certainly in the UK, were seen as changing sides and giving up clinical duties. This scepticism and the resultant lack of involvement by clinicians in management and leadership roles led to a schism between the medical profession and those in charge of managing services, which only served to make both sides easier targets for the political agenda and the manipulation of public opinion through the media. This distrust has had a detrimental effect on some health services, especially when corporate models of services from other industries have been attempted with little involvement of clinicians. The resulting powerlessness felt by clinicians has affected the morale of the workforce and made medicine a less attractive career option.

Leaders are not born as leaders. They utilise their strengths for their purpose. Personality traits can be suppressed, weaknesses hidden and strengths can be played up. Understanding organisational culture is not always intuitive, although intuition may enable the individual to deal with challenges. For psychiatrists, certain skills required for leadership are inherent in training, such as understanding of human dynamics, dealing with groups and collaborating with teams. One can learn about business planning, assessing risks, dealing with others, identifying resources and being flexible, but inspiration and vision may not be learnt as such.

\section{Conclusions}

Medical training requires a high level of intellectual functioning. Confident decision-making and knowledge are important aspects of one's clinical skills. These skills are central to being a leader, as is the ability to reflect on one's own decisionmaking processes. Psychiatrists are in an advantageous position of having skills they learn through clinical work which they can use to develop their own leadership abilities through reflective practice. However, there is a great need to provide opportunities for those clinicians with leadership abilities to develop. Greater say in how services function and deliver will lead to greater confidence among clinicians in general that patient care remains central to changes and longer-term planning and is not being hijacked by an external agenda.

\section{References}

Firth-Cozens, J. (2006a) A perspective on stress and depression. In Understanding Doctors' Performance (eds J. Cox, J. King, A. Hutchinson, et al), pp. 22-37. Radcliffe.

Firth-Cozens, J. (2006b) Leadership and the quality of health care. In Understanding Doctors' Performance (eds J. Cox, J. King, A. Hutchinson, et al), pp. 122-133. Radcliffe.

Ghodse, H. \& Galea, S. (2006) Misuse of drugs and alcohol. In Understanding Doctors' Performance (eds J. Cox, J. King, A. Hutchinson, et al), pp. 38-47. Radcliffe.

Gibson, K., Kartsounis, L. \& Kopelman, M. (2006) Cognitive impairment and performance. In Understanding Doctors' Performance (eds J. Cox, J. King, A. Hutchinson, et al), pp. 48-60. Radcliffe.

Harvard Business School Press (2006) Decision Making: 5 Steps to Better Results. Harvard Business Essentials. Harvard Business School Press.

Kotter, J. P. (1998) What Leaders Really Do (Harvard Business Review Book Series). Harvard Business School Press.

Mach, E. (1905) Knowledge and Error (trans. 1976). Reidel.

Newell, B. R., Lagnado, D. A. \& Shanks, D. R. (2007) Straight Choices: The Psychology of Decision Making. Psychology Press.

Reason, J. (1990) Human Error. Cambridge University Press.

Yates, J., Veinott, E. \& Patalamo, A. (2003) Hard decisions, bad decisions. In Emerging Perspectives on Judgement and Decision Research (eds S. L. Schneider \& J. Shanteau), pp. 13-63. Cambridge University Press.

\title{
Care for elderly people with mental illness: a global problem
}

\section{David Skuse}

Behavioural and Brain Sciences Unit, Institute of Child Health, London, UK, email dskuse@ich.ucl.ac.uk

\begin{abstract}
A the median age of populations around the world increases, due to the provision of better diets and better medical care, the number of elderly persons vulnerable to mental illness will inevitably increase too. We are not good at providing high-quality geriatric care, even in highincome countries. For example, Age Concern (a UK-based charity) states on its website: 'Health and social care services have made some progress in tackling age discrimination, but older people still report feeling that they have had second class treatment and care simply because of their age' (www.ageconcern.org.uk/AgeConcern/ageismin-healthcare.asp). How much worse these matters are in
\end{abstract}

low- and middle-income countries is the subject of our theme in this issue. We have drawn articles from three distinct geographic regions: India, Africa and South-East Asia. We often assume that cultural factors in lowerincome areas lead to greater respect for, and better care of, the elderly than we experience in many parts of the Western hemisphere. This appears to be a misapprehension, and attitudes towards the elderly are changing as the impact of industrialisation increases.

Dr Henry and colleagues discuss the importance of supporting those caring for elderly people in India, and the services that could be provided for a geriatric population with 
a range of dementias, psychoses and emotional disorders. Group sessions aimed primarily at supporting the carers of elderly relatives appeared to be of some benefit.

The article by Drs Clausen and Wilson addresses a wider issue: the prospect of an ageing population in Africa. They point out that health budgets are severely limited for all African countries, and that priority is given to the needs of the younger generations, who are economically active. As the longevity of African adults increases in years to come, it is essential to maintain as high a proportion as possible of the ageing population in economic activity. This will entail a tradeoff between the cost of providing social and medical care, and the ability of that population to contribute to wealth generation. Currently, the provision of services to older patients with mental illnesses in most African countries is non-existent.
Finally, Professor Kua Ee Heok discusses the hidden burden of dementia among the elderly in South-East Asia. There is evidence that a very small proportion of all cases have been identified, and this is in part attributable to inadequate training of general practitioners. But even if identification were to be improved, would this lead to a higher priority being given to the care of elderly people with mental illness in the health services of that region? There is a change coming in the attitude of young people, who traditionally have cared for their extended families in multigenerational homes, such as the hutongs in Beijing. These young people want to live apart from their parents nowadays, in modern apartments, and community services have yet to compensate for that rapid change in cultural attitudes.

\title{
Group intervention for carers of geriatric patients: experiences from a clinic in India
}

\author{
J. Henry, ${ }^{1}$ A. Jagannathan, ${ }^{1}$ K. Bhavana, ${ }^{1}$ B. Thomas, ${ }^{1}$ S. Bharath, ${ }^{2}$ \\ M. Varghese, ${ }^{2}$ O. P. Jhirwal' ${ }^{2}$ and P. T. Sivakumar ${ }^{2}$
}

'Department of Psychiatric Social Work, National Institute of Mental Health and Neurosciences (NIMHANS), ${ }^{2}$ Department of Psychiatry, NIMHANS, Bangalore, India email srikala.bharath@gmail.com

Sasting ixty per cent of the global elderly population live in lowand middle-income countries, and this proportion was expected to rise to $70 \%$ by 2010 (International Institute of Ageing, 2001; Ferri et al, 2005). The 2001 Indian census found over 70 million people aged 60 years or more (considered senior citizens according to the Indian National Policy on Older Persons). Most of those senior citizens live with younger family members and are dependent on them for financial and social support. Hence, any physiological and psychological changes in the older family members affect the younger supportive members as well.

According to the findings of the 10/66 Dementia Research Network (Shaji et al, 2003), older people in low- and middleincome countries are 'indivisible from their younger family members'. Despite larger households being associated with lower levels of carer strain, this was in fact as high as in high-income countries. Prince (2004) found that many family members had to cut back on work in order to care for an older individual with dementia.

The need to provide respite care for family members in the Indian context has been highlighted by Rao \& Shaji (2007). Collaborative care, through the use of support groups for carers that provide both information as well as outlets to vent pent up emotions, has become increasingly popular across countries. Group interventions that are educational and problem-focused and that discuss behavioural management have been found to be particularly useful (Haley, 1997) and they serve to delay nursing-home placement (Mittelman et al, 1996).
This article describes the development and pilot testing of a group intervention module for the carers of geriatric patients at a tertiary-care hospital in India. The work reported in this paper was conducted at a specialty out-patient geriatric clinic run once a week by the Department of Psychiatry at a tertiary centre, the National Institute of Mental Health and Neurosciences (NIMHANS), Bangalore. The catchment area comprises both urban and rural areas of four adjoining southern states of India (Karnataka, Andhra Pradesh, Tamil Nadu and Kerala) and the centre receives referrals from the rest of the country. The clinic team comprises four geriatric psychiatrists, four social workers, a neurologist and two psychologists. The clinic provides services for a heterogeneous geriatric population with diagnoses that include dementia, psychosis, mood disorders and other psychiatric disorders.

\section{Method}

The geriatric clinic team planned a regular group intervention programme for the carers of the patients who attend the clinic. Initially, three focus group discussions were held with 17 carers. 'Cue questions' on the recognition of symptoms, behavioural management, medical care and follow-up, use of support systems, carer burden and social welfare measures for senior citizens were used to facilitate these discussions. The findings from the focus groups and inputs from experts in the field of geriatric psychiatry were then used to prepare an intervention module. 